\title{
Plastic life-history variation along the course of a steep mountainous river in male Cottus hangiongensis (Pisces: Cottidae)
}

\author{
Akira Goto • Hideaki Arioka • Ryota Yokoyama \\ Received: 14 June 2013 / Accepted: 2 October 2013 / Published online: 18 October 2013 \\ (C) The Author(s) 2013. This article is published with open access at Springerlink.com
}

\begin{abstract}
To elucidate the causes of clinal life-history variation in male freshwater amphidromous Cottus hangiongensis found along the river courses, we examined the genetic composition of upstream, midstream, and downstream groups using microsatellite DNA markers and different growth patterns among juvenile individuals before and after they ascended a small, steep mountainous river in southern Hokkaido, Japan. Microsatellite allele frequencies indicated that the samples collected from three different habitats appeared to represent a panmictic population and no genetic differences were found among the three groups. Ecological field surveys showed that juveniles greatly depended on
\end{abstract}

A. Goto $\cdot$ R. Yokoyama

Field Science Center for Northern Biosphere,

Hokkaido University,

3-1-1 Minato-cho, Hakodate, Hokkaido 041-8611, Japan

H. Arioka

Laboratory of Aquatic Animal Breeding,

Graduate School of Fisheries Sciences,

Hokkaido University,

3-1-1 Minato-cho, Hakodate, Hokkaido 041-8611, Japan

Present Address:

A. Goto $(\bowtie)$

Department of Science of Environmental Education,

Hokkaido University of Education,

1-2 Hachiman-cho, Hakodate, Hokkaido 040-8567, Japan

e-mail: akir@fish.hokudai.ac.jp

Present Address:

R. Yokoyama

Civil Engineering \& Eco-Technology Consultants, Co., Ltd.,

2-23-2 Higashi-ikebukuro, Toyoshima,

Tokyo 170-0013, Japan the timing of their ascent into the river from the sea, and that larger juveniles were able to disperse to more upstream areas and grew larger during the period after they migrated up to the mouth of the river. These results suggested that clinal life-history variations may be induced through phenotypic plasticity and that earlier ascent of juveniles from the mouth of river may be an important source of variation.

Keywords Life-history traits · Juvenile upstream migration $\cdot$ Heterogeneous environment .

Amphidromous sculpin

\section{Introduction}

Phenotypic plasticity, or changes in the phenotypic expression of a single genotype as a function of the environment, has broad significance because it unites perhaps all fields of biology: encompassing genetics, development, ecology, evolution, and even biophysics, physiology, and behavioral science (Scheiner 1993; Dewitt and Scheiner 2004). Within a population, environmentally induced phenotypic traits may be an important source of life-history and genetically induced variation. Genetically based intraspecific variation could arise if the population had a substructure of reproductively isolated subunits (Hendry et al. 1999) and was sufficiently small to yield genetic drift. Three main sources of life-history variation within a fish population can be distinguished: (1) body size (Wootton 1990); (2) environmental conditions (Jonsson et al. 1996; LobonCervia et al. 1997; Morita et al. 1999; Baker and Foster 
2002); and (3) breeding dates (Bagenal 1971; Ware 1975; Candolin 1998; Hendry et al. 1999; Poizat et al. 1999). These patterns have been described as morphological constraints, proximal environmental effects, or adaptations (Poizat et al. 2002).

The freshwater amphidromous sculpin, Cottus hangiongensis Mori, which is a small bottom-dwelling fish that has a polygynous mating system with eggs guarded by a parental male until hatching, is restricted to northern Japan, Korea and southern Sakhalin, Russia (Goto 1986, 1987a, 1990). In the Daitobetsu River located in the southern part of Hokkaido Island, Japan, male $C$. hangiongensis are known to have clinal differences in population density, sex ratio, age composition and life history along the course of rivers (Goto 1987b, 1989b, 1993a). Sexual maturity occurs earlier in life when fish are a small size in downstream habitats, versus later in life when fish are a larger size in upstream habitats (Goto 1987b, 1989c), although most females are restricted to downstream habitats and reach the first maturity at about $55 \mathrm{~mm}$ or more in standard length (Goto 1989b). During the reproductive season, usually in April to May, the larger males inhabiting the upstream area migrate downstream, where their spawning grounds are located, and mate with many females. The smaller males in the downstream habitats stay there and mate with only a few or no females (Goto 1987b, 1993b; Goto and Nakano 1993).

In this study, we sought to elucidate the causes and formation mechanisms of clinal life-history variation in male $C$. hangiongensis along the course of the Daitobetsu River. We examined the genetic heterogeneity of upstream, midstream, and downstream habitat groups using microsatellite markers to infer whether such lifehistory variation was environmentally induced and surveyed the differential growth patterns among juvenile males of this species before and after ascent to the mouth of the river.

\section{Materials and methods}

Sample collection

Adult male C. hangiongensis were collected in August 2005 from upstream (St. 1), midstream (St. 2), and downstream (St. 3) sites of the Daitobetsu River. The river is about $21 \mathrm{~km}$ in length and has a considerably steep gradient of channels (4/1000-9/1000 in the slope of river bed) in the lower course from the mouth of the river to $4 \mathrm{~km}$ from the upstream site (Fig. 1). Thirtynine $(79.5 \pm 2.1 \mathrm{~mm}$ standard length [SL], mean and SD), 26 (98.8 $\pm 4.8 \mathrm{~mm} \mathrm{SL})$, and $27(103.6 \pm 2.0 \mathrm{~mm}$ $\mathrm{SL})$ adult individuals were collected from the upstream, midstream, and downstream sites, respectively (Table 1). All fish specimens were immediately fixed in $99.5 \%$ ethanol and stored at the laboratory of Faculty of Fisheries, Hokkaido University, Hakodate, Japan, until a microsatellite (msDNA) analysis was performed.

To examine the body size of downstream drifting larvae of $C$. hangiongensis and the duration of their drift, individuals were collected at the mouth of the river using a larva net (net diameter: $50 \times 30 \mathrm{~cm}$, net length: $90 \mathrm{~cm}$, net mesh size: $1 \mathrm{~mm}$ ) at 10-day intervals during the period from early May to mid-June in 2005. The standard length of larvae was measured to the nearest $0.1 \mathrm{~mm}$ by using a caliper. To estimate the age (in days) of juvenile male $C$. hangiongensis transitioning from the sea to the mouth of the river, collection of juvenile samples was carried out from late June to mid-July in 2005.

Genetic analysis of heterogeneity among the three different habitat groups

Total DNA extracted from the fin clips was preserved in $99.5 \%$ ethanol using methods previously described by Yokoyama and Goto (2005). Samples were genotyped at five microsatellite loci: Cgo56MEHU, Cgo1016PBBE, Cgo05ZIM, Cgo18ZIM, and Cgo33ZIM, which were derived from C. gobio (Englbrecht et al. 1999). Individual amplification volumes (total $10 \mu \mathrm{L}$ ) contained $1 \mu \mathrm{L}$ template DNA and $2 \mu \mathrm{M}$ forward and reverse primers in 2× QIAGEN Multiplex PCR Master Mix containing HotStart Taq DNA polymerase. An initial activation step $\left(15 \mathrm{~min}, 95^{\circ} \mathrm{C}\right)$; followed by 35 cycles of denaturation (30 s, $94^{\circ} \mathrm{C}$ ), annealing (90 s, see Englbrecht et al. [1999] for annealing temperatures for each primer set), and an extension phase $\left(60 \mathrm{~s}, 72{ }^{\circ} \mathrm{C}\right)$; followed by a final extension hold $\left(30 \mathrm{~min}, 60^{\circ} \mathrm{C}\right)$. Amplified products were analysed using an ABI PRISM 3130 Genetic Analyzer (Life Technologies Foster City, CA, USA) with LIZ500 size standards (Life Technologies), and Peak Scanner Software v1.0 (Life Technologies) was used for fragment analysis. msDNA genotype frequencies for each of the three habitat groups were tested for deviations from Hardy-Weinberg equilibrium (HWE) and linkage 


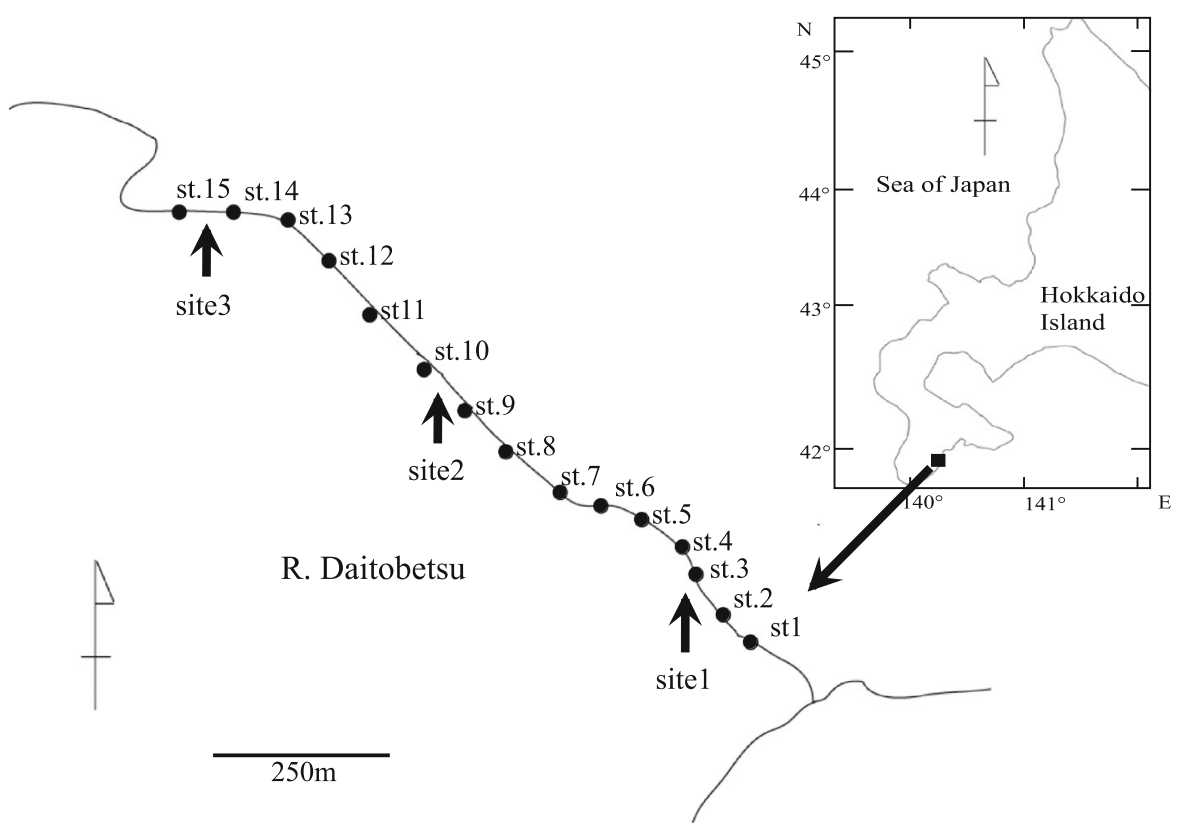

Fig. 1 Map showing the location of the Daitobetsu River and sampling sites for adult males (black circle) and upstream migrating juveniles (black circle) of Cottus hangiongensis

disequilibrium by an exact test using ARLEQUIN version 3.1 (Excoffier et al. 2005).

Age and size determination for the juveniles migrating upstream from the sea

Sagittal otoliths extracted from juvenile individuals following upstream migration from the sea were used to count the number of daily rings under a binocular microscope. Estimated age (days) after hatching and duration (days) of marine life were measured according to the methods described by Tsukamoto and Kajihara (1987) and Goto and Arai (2006). The estimated age was treated as the duration of marine life of the individual fish because the larvae of $C$. hangiongensis appeared to flow down to the sea less than $3 \mathrm{~h}$ after hatching in a small stream, such as the Daitobetsu River (Goto 1981).

Field survey on larval downstream drift and juvenile upstream migration

To elucidate the early life history and upstream migration of juveniles, we examined the ecological aspects of larval drift to the sea and the transition of juveniles from the sea to the river mouth. In the period from late April to early June in 2005, drifting C. hangiongensis larvae were collected using a plankton net (net diameter: $50 \times$ $30 \mathrm{~cm}$, net mesh size: $1 \mathrm{~mm}$ ) at 2-h intervals after sunset. Using the data on larval drift, we estimated the duration
Table 1 Number and body length of adult Cottus hangiongensis collected from the Daitobetsu River in 2005 used for microsatellite DNA analysis

\begin{tabular}{|c|c|c|c|c|c|}
\hline \multirow[b]{2}{*}{ Collection site } & \multirow[b]{2}{*}{ Date of collection } & \multirow[b]{2}{*}{ Number of fish } & \multicolumn{2}{|l|}{ Sex } & \multirow{2}{*}{$\begin{array}{l}\text { Standard length } \\
\text { Mean } \pm \text { SD }(\mathrm{mm})\end{array}$} \\
\hline & & & Male & Female & \\
\hline Site 1 & 1 and 15 August & 39 & 1 & 38 & $79.5 \pm 2.1$ \\
\hline Site 2 & 3 and 13 August & 24 & 24 & 2 & $98.8 \pm 4.8$ \\
\hline Site 3 & 1 and 10 August & 27 & 27 & 0 & $103.6 \pm 2.0$ \\
\hline Total & & 92 & 52 & 40 & \\
\hline
\end{tabular}


of larval drift, the number of larvae collected on each day surveyed, and the body size of larvae collected.

During the period from late May to mid-June, juveniles transitioning from the sea to the mouth of the river were collected using a trap net (length, $120 \mathrm{~cm}$; width, $80 \mathrm{~cm}$; height, $30 \mathrm{~cm}$; mesh size, $2 \mathrm{~mm}$ ). The net was positioned directly downstream of the mouth of the river on every sampling day. The collected fish were removed from the net twice a day, at 07:00 and 19:00 h, and the number of fish was counted at each sampling time. The SL of the collected fish was measured to the nearest $0.1 \mathrm{~mm}$ using a caliper.

To determine the size composition dynamics of ascending juveniles, regression analysis was used to examine the relationship between the SL ( $\mathrm{mm}$ ) of the ascending juveniles and the progress time (days) after the start of ascension from the sea.

To explain the upstream dispersal of juvenile individuals in the lower course (from the mouth of river to $1.5 \mathrm{~km}$ upstream) of the Daitobetsu River, 15 sampling sections were established (Fig. 1). Juveniles were collected from each sampling section using a backpack electro fisher (Smith Root Inc., USA) during the period from August to November 2005 and during February 2006. The SL of the collected juvenile fish was measured to the nearest $0.1 \mathrm{~mm}$. To clarify the relationship between the size of juveniles (mm SL) and distance (m) from the mouth of the river, regression analysis was carried out using the SL of juveniles $(L s)$ as the dependent variable and the distance from the mouth of the river $(D m)$ as the independent variable.

\section{Statistic analyses}

Differences in genotype frequencies were tested among samples from the three different habitats using the chisquare test. The goodness-of-fit test for the HWE was performed for samples from each of the three habitats and all samples of adult Cottus hangiongensis using the chi-square test.

Correlation coefficients $\left(r^{2}\right)$ between the mean total length $(\mathrm{mm})$ of downstream drifting larvae and the sampling date, the SL of upstream migrating juveniles ( $\mathrm{Lm}$ ) and the sampling date, the date when the juveniles migrated up to the river mouth $(D m)$ and the $L m$, the $D m$ and the duration of marine life $(L s)$, the $D h$ and the $L s$, and the $L m$ and the $L s$ were assessed with single regression analyses. Statistical $p$-values of 0.05 or less were treated as statistically significant. All statistical analyses were performed using the statistical software package R 2.62 (R. Development Core Team 2008).

\section{Results}

Genetic heterogeneity among the three different habitat groups

Microsatellite DNA marker analysis revealed no genetic differences among the three habitat groups at three loci, although a significant difference was found at a single locus (Cgo05ZIM, Table 2). When the data for all the fish samples collected from the three different habitats were combined, no loci exhibited a significant departure from the HWE (Table 2).

Larval downstream drift and juvenile upstream migration

Downstream drift of larvae of this species was detected mostly during the period from mid-May to early June 2005 , with a surge on June 5,2005 . The mean total length of drifting larvae was $7.6 \pm 0.4 \mathrm{~mm}(n=347)$. No significant correlation was found between the mean total length of larvae at each sampling day and the sampling date (Correlation coefficient $r^{2}=0.002, p=0.608$; Fig. 2).

Upstream migration of juvenile fish having a mean SL of $13.9 \pm 0.03 \mathrm{~mm}(n=649)$ began on June 10, 2005 and ceased on June 26, 2005 (Fig. 3). The SL of upstream migrating juveniles $(\mathrm{Lm})$ tended to decrease over time $\left(r^{2}=0.028, p<0.001\right.$; Fig. 4). Otolith daily rings and hatching marks were observed in upstream migrating juvenile $C$. hangiongensis. A significant correlation was found between the date when the juveniles migrated to the mouth of the Daitobetsu River from the sea (juvenile migration date: $D m$ ) and the SL of juveniles $(L s)$, as estimated by otolith daily rings analysis in $2005\left(r^{2}=0.04, p<0.0001\right.$; Fig. 5). Analysis revealed that the upstream migration of juveniles occurred in 33- to 60-day-old individuals, indicating that the hatching dates $(D h s)$ of upstream migrating juveniles ranged from April 21 to May 17, 2005.

A significant positive correlation was detected between the $D m$ and the duration of marine life $(L s)$ in each juvenile fish, as estimated from otolith daily rings $\left(r^{2}=0.349, p<0.0001\right.$; Fig. 6a). Similarly, a significant negative correlation was found between the $D h$ and $L s$ 
Table 2 Genotype frequencies and Hardy-Weinberg expectation at 5 loci, and the results of chi-square test for goodness of fit between observed and expected values

\begin{tabular}{|c|c|c|c|c|c|c|c|c|c|}
\hline \multirow[t]{2}{*}{ Locus } & \multirow[t]{2}{*}{ Genotype } & \multicolumn{2}{|l|}{ Site 1} & \multicolumn{2}{|l|}{ Site 2} & \multicolumn{2}{|l|}{ Site 3} & \multicolumn{2}{|c|}{ All the samples } \\
\hline & & Observed & Expected & Observed & Expected & Observed & Expected & Observed & Expected \\
\hline Cgo1016PBBE & $a / a$ & 39 & 39 & 26 & 26 & 27 & 27 & 92 & 92 \\
\hline \multirow[t]{7}{*}{ Cgo33ZIM } & $a / a$ & 28 & 28.6 & 17 & 16.08 & 17 & 17.04 & 62 & 61.74 \\
\hline & $a / b$ & 9 & 7.92 & 6 & 8.04 & 8 & 7.3 & 23 & 23.2 \\
\hline & $a / c$ & 1 & 0.88 & 1 & 0.8 & 1 & 1.62 & 3 & 3.32 \\
\hline & $b / b$ & 0 & 0.48 & 2 & 0.88 & 0 & 0.68 & 2 & 2.09 \\
\hline & $b / c$ & 0 & 0.12 & 0 & 0.2 & 1 & 0.34 & 1 & 0.62 \\
\hline & $c / c$ & 0 & 0 & 0 & 0 & 0 & 0.02 & 0 & 0.03 \\
\hline & & \multicolumn{2}{|l|}{$(P=0.941)$} & \multicolumn{2}{|l|}{$(P=0.691)$} & \multicolumn{2}{|l|}{$(P=0.808)$} & \multicolumn{2}{|l|}{$(P=0.998)$} \\
\hline \multirow[t]{4}{*}{ Cgo56MEHU } & $a / a$ & 36 & 36.2 & 26 & 26 & 27 & 27 & 89 & 89.01 \\
\hline & $a / b$ & 2 & 1.95 & 0 & 0 & 0 & 0 & 2 & 1.98 \\
\hline & $b / b$ & 0 & 0.03 & 0 & 0 & 0 & 0 & 0 & 0.01 \\
\hline & & \multicolumn{4}{|l|}{$(P=0.98)$} & & & \multicolumn{2}{|l|}{$(P=0.995)$} \\
\hline \multirow[t]{11}{*}{ Cgo05ZIM } & $a / a$ & 14 & 10.99 & 9 & 7.54 & 7 & 4.72 & 30 & 22.88 \\
\hline & $a / b$ & 9 & 12.96 & 4 & 5.38 & 2 & 6.16 & 15 & 24.4 \\
\hline & $a / c$ & 1 & 2.82 & 2 & 2.12 & 1 & 2.41 & 4 & 8.64 \\
\hline & $a / d$ & 2 & 2.25 & 4 & 0.09 & 6 & 0.72 & 12 & 12.2 \\
\hline & $b / b$ & 7 & 3.56 & 0 & 5.92 & 5 & 3.7 & 12 & 6.3 \\
\hline & $b / c$ & 0 & 1.62 & 1 & 1.62 & 0 & 3.7 & 1 & 4.56 \\
\hline & $b / d$ & 0 & 1.3 & 5 & 0.58 & 3 & 2.41 & 8 & 6.44 \\
\hline & $c / c$ & 1 & 0.14 & 0 & 0.96 & 4 & 2.01 & 5 & 0.76 \\
\hline & $c / d$ & 2 & 0.28 & 0 & 0.63 & 0 & 1.45 & 2 & 2.28 \\
\hline & $d / d$ & 0 & 0.08 & 1 & 1.16 & 0 & 0.72 & 1 & 1.54 \\
\hline & & \multicolumn{2}{|l|}{$(P=0.481)$} & \multicolumn{2}{|l|}{$(P=0.005)$} & \multicolumn{2}{|l|}{$(P=0.674)$} & \multicolumn{2}{|l|}{$(P=0.364)$} \\
\hline \multirow[t]{11}{*}{ Cgo18ZIM } & $a / a$ & 17 & 15.82 & 10 & 9.48 & 11 & 9.85 & 38 & 34.84 \\
\hline & $a / b$ & 2 & 2.81 & 6 & 4.15 & 4 & 3.69 & 12 & 10.96 \\
\hline & $a / c$ & 6 & 7.73 & 5 & 7.11 & 5 & 7.38 & 16 & 22.58 \\
\hline & $a / d$ & 3 & 2.81 & 1 & 1.78 & 1 & 1.23 & 5 & 5.8 \\
\hline & $b / b$ & 0 & 0.13 & 0 & 0.45 & 0 & 0.35 & 0 & 0.8 \\
\hline & $b / c$ & 1 & 0.69 & 1 & 1.56 & 2 & 1.38 & 4 & 3.52 \\
\hline & $b / d$ & 1 & 0.25 & 0 & 0.39 & 0 & 0.23 & 1 & 0.91 \\
\hline & $c / c$ & 2 & 0.95 & 2 & 1.33 & 2 & 1.38 & 6 & 3.52 \\
\hline & $c / d$ & 0 & 0.69 & 2 & 0.67 & 1 & 0.46 & 3 & 1.86 \\
\hline & $d / d$ & 0 & 0.13 & 0 & 0.08 & 0 & 0.04 & 0 & 0.21 \\
\hline & & \multicolumn{2}{|l|}{$(P=0.814)$} & \multicolumn{2}{|l|}{$(P=0.745)$} & \multicolumn{2}{|l|}{$(P=0.973)$} & \multicolumn{2}{|l|}{$(P=0.746)$} \\
\hline
\end{tabular}

$\left(r^{2}=0.249, p<0.001\right.$; Fig. $\left.6 b\right)$. On the other hand, significant positive correlations were found between the distance to the collecting site from the sea $(D n)$ and the $L s$ in September $\left(n=36, r^{2}=0.720, p<0.001\right)$, October $\left(n=38, r^{2}=0.264, p<0.001\right)$, and November in 2005 $\left(n=24, r^{2}=0.231, p<0.05\right)$, and February in 2006 $\left(n=29, r^{2}=0.324, p<0.01\right.$; Fig. 7).

\section{Discussion}

Genetic homogeneity among the three different habitat groups

The limited microsatellite DNA analysis showed no genetic heterogeneity among the three different habitat 


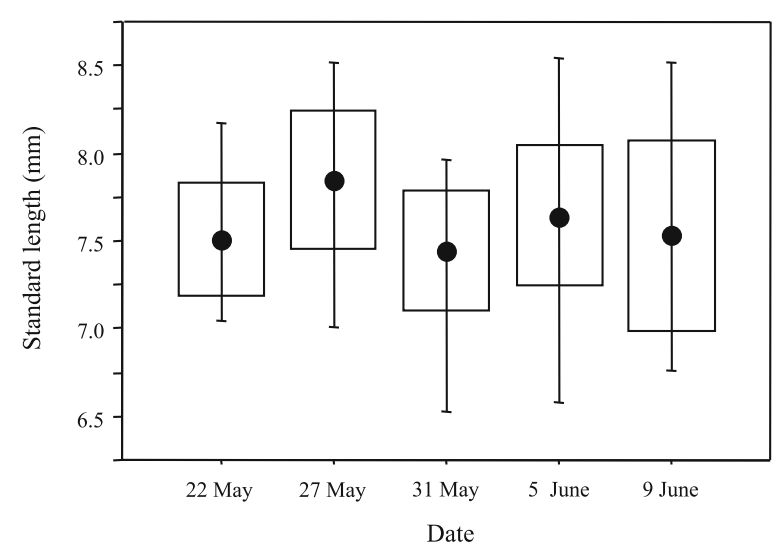

Fig. 2 Standard length of downstream-migrating Cottus hangiongensis larvae at each sampling day from 22 May to 9 June in the Daitoubetsu River in 2005. Dot, square, and vertical bar indicate the mean, the standard deviation and the range, respectively

groups of $C$. hangiongensis along the course of the Daitobetsu River. Additionally, the combined fish samples collected from the three habitats fit the HWE. These results implied that the $C$. hangiongensis population was a single panmictic population. This assumption was supported by the results of genetic composition examination using polymorphic allozyme loci for the upstream and downstream adult samples of the $C$. hangiongensis population (Usui and Goto 1987) and of a common garden experiment on rearing 1+ aged male individuals of this species under different density conditions in which the maturity of fishes was delayed at low density (Goto 1993a). Thus, these results suggest that clinal life-history variation in males of this species (Goto 1988, 1989c, 1993a) may be a result of phenotypic plasticity. To obtain a more reliable result of the panmictic, however, reexamination of the homogeneity among a number of habitat groups of this species using a greater number of polymorphic microsatellite DNA markers is necessary in the near future.

Downstream and upstream migration and growth during early ontogenetic development

For downstream drift of larvae, no significant correlation was found between body size and the date of larval drift. This result indicated that the larvae drifted downstream could reach the mouth of the river while maintaining almost the same body size throughout the period of their downstream drift. For upstream migration of juveniles, our otolith daily rings analysis revealed that juveniles hatching later had a shorter larval duration in the marine pelagic life stage. This suggests that juveniles experiencing marine pelagic life stage later in the season migrated earlier to the mouth of the river from the sea, probably due to their increased growth in the sea under higher water temperature.

In Lake Biwa, Japan, the landlocked ayu Plecoglossus altivelis altivelis, which was derived from the freshwater amphidromous population, includes the small "residents," large "spring migrants," and intermediate "summer migrants" (Tsukamoto et al. 1987). These
Fig. 3 Chronological changes in the number of upstream migrating juvenile Cottus hangiongensis collected in the mouth of the Daitobetsu River in 2005. The surges are found on 12th and 17 th June

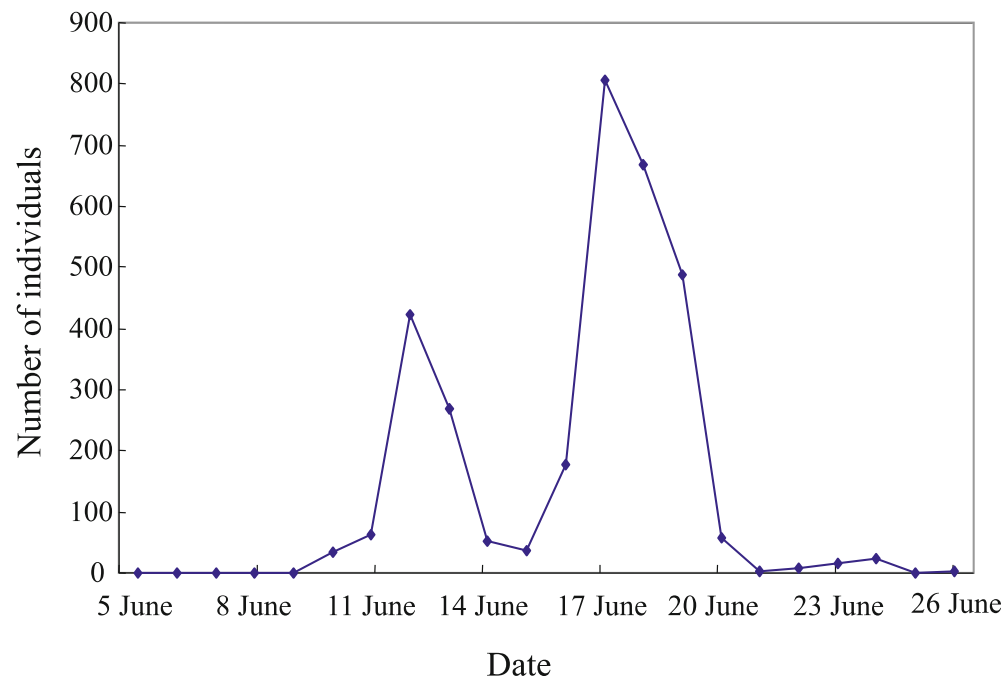

Date 


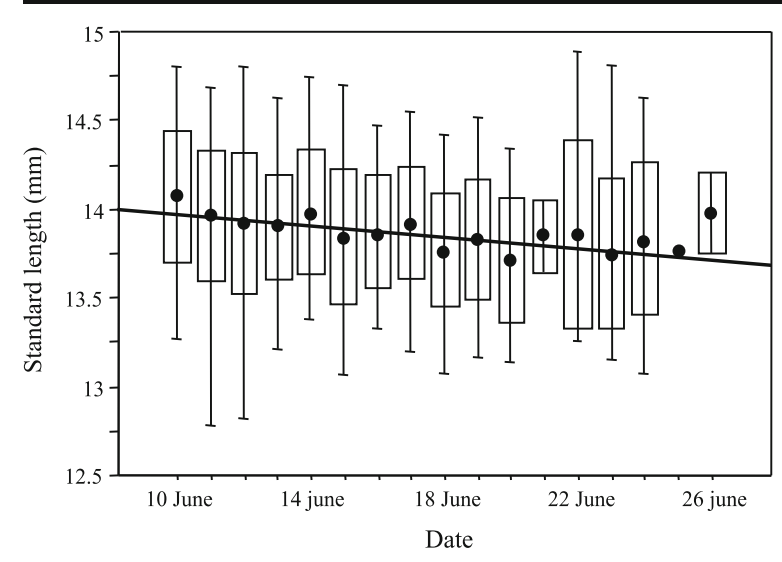

Fig. 4 A relationship between the day migrating to the mouth of the Daitobetsu River from the sea and the mean standard length of Cottus hangiongensis juveniles. Dot, square, and vertical bar indicate the mean, the standard deviation and the range, respectively. The line in figure indicates a linear regression showing a significant negative correlation between the two variables

different subpopulations migrate to the mouths of rivers from the lake at different times of the season and have different ages and sizes at their time of migration (Tsukamoto et al. 1987). This study found that juvenile $P$. altivelis altivelis with earlier birth dates and/or large growth rates migrate upstream earlier. However, this was not the case with the amphidromous sculpin $C$. hangiongensis.

In the $C$. hangiongensis population, the date of upstream migration of juveniles was strongly influenced by the growth rates of larvae during the marine pelagic life stage, and significant positive correlations were found between the distance to the collecting site from the sea and the SL of juvenile fishes during upstream migration in the river from September to February in the next year. These results demonstrated that a clinal bodysize variation in the juvenile fishes had already been formed along the downstream course of the river after about 3 months since the ascent of juveniles to the mouth of the river and may imply that larger juveniles inhabiting the downstream areas can disperse to more upstream areas and grow larger during the period following their migration upstream to the mouth of the river, most likely due to the abundance of space and food for individual $C$. hangiongensis juveniles in the upstream areas (Goto 1989a, b, 1993a). Therefore, it is possible that such a body-size variation in the juvenile fishes just having recently ascended to the mouth of the river may be one of the proximate causes for forming the clinal life-history variation in this species.

Formation mechanisms of plastic life-history variation along the course of a river

Life history theory predicts that delayed maturation at larger sizes and older ages occurs when juvenile mortality strongly increases with decreasing growth, or when both juvenile and adult mortality increase with decreasing growth rate (Stearns and Koella 1986; Stearns 1989, 1992; Kawecki and Stearns 1993; Jonsson et al. 1996; Taborsky 2006). It is well known that these conditions apply when mortality decreases with body size, as has often been found in fish (Henderson et al. 1988;
Fig. 5 A relationship between the hatching date $\left(D_{\mathrm{h}} \mathrm{s}\right)$ and the duration of marine life $\left(D_{\mathrm{h}} \mathrm{s}\right)$ of upstream-migrating Cottus hangiongensis juveniles collected in the mouth of the Daitobetsu River in 2005. The line in figure indicates a linear regression showing a significant negative correlation between the two variables

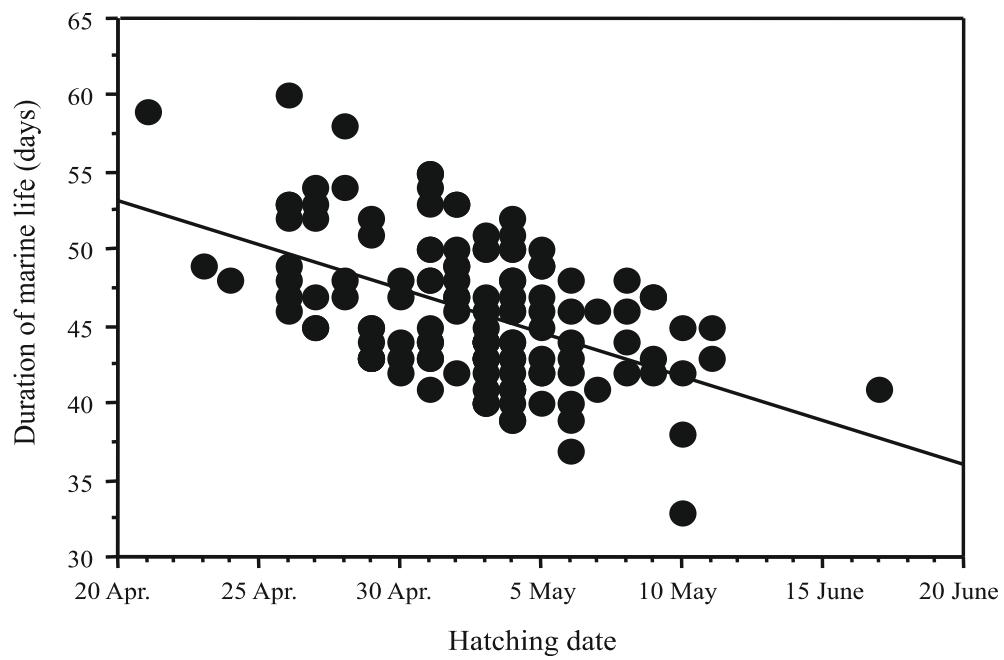


Fig. 6 Relationships between the days after hatching and the number of otolith daily rings (a), and between the days after hatching and the standard length (b) of downstream-migrating Cottus hangiongensis larvae in the Daitobetsu River. The line in figure (a) indicates a linear regression showing a significant negative correlation between the two variables, and line in figure (b) indicates that showing a significant positive correlation between them

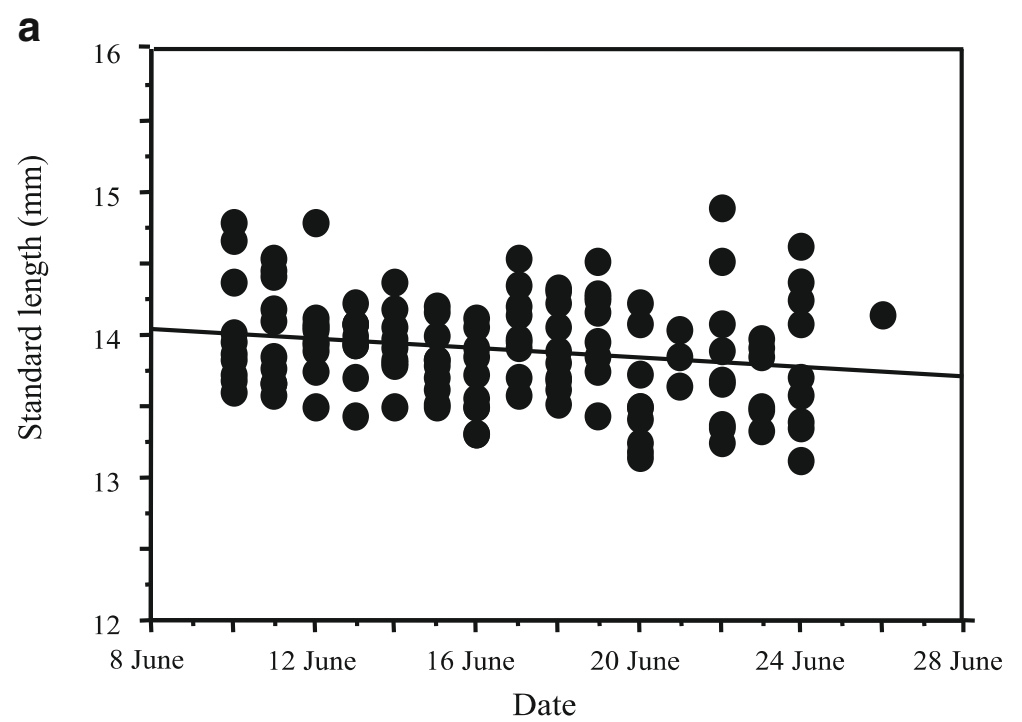

b

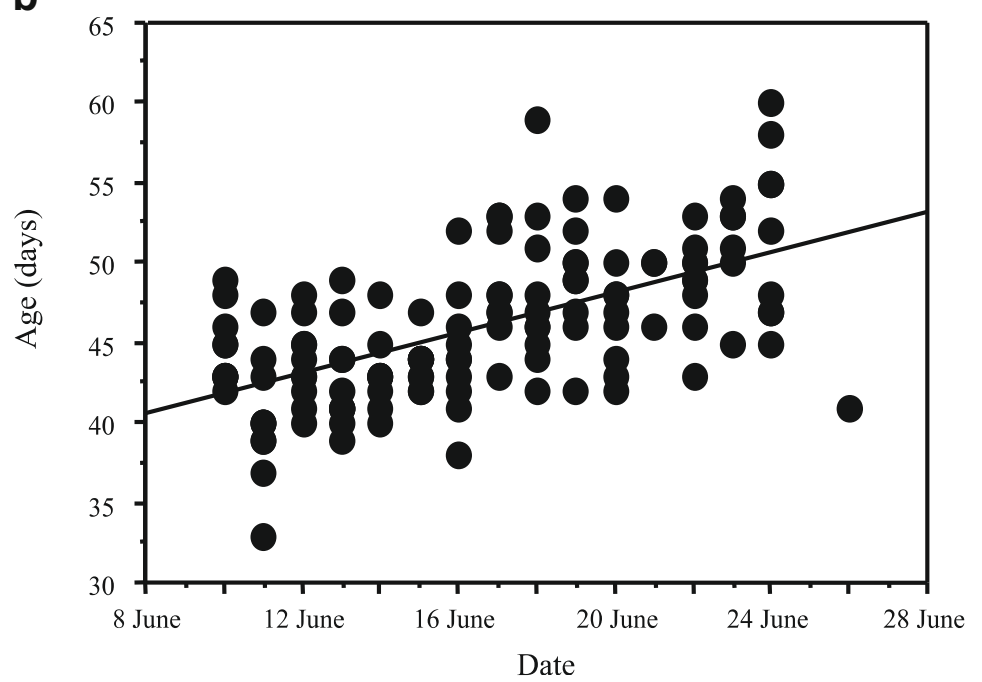

Wootton 1990; Metcalfe and Monaghan 2001; Taborsky 2006).

In male $C$. hangiongensis, the first maturation of adult individuals that inhabit the upstream area may be delayed until they have reached a larger size and are older than those in the downstream habitat group. This may occur due to the high mortality risk during the juvenile period, when fish migrate from the downstream area to the upstream area. Such high mortality is possibly caused by factors such as predation by the white-spotted charr Salvelinus leucomaenis and carnivorous birds, such as the common kingfisher Alcedo atthis and the brown dipper Cinclus pallasii, and by exhaustion as a result of energy loss from upstream migration. Despite such differences in mortality risks resulting from the life-history variation found in other freshwater fishes, our present empirical study may contribute to verifying the validation of the prediction proposed by Stearns (1992) and Taborsky (2006) that juvenile growth conditions may initiate a feedback loop resulting in individual life-history trajectories located somewhere between 'slow juvenile growth-early reproduction-high reproductive rate' and 'fast juvenile growth-late reproduction-low reproductive rate'. In males of this species, as a result, clinal life-history variation would be formed by the following process: when the upstream migrating juveniles stay in the downstream region, they grow slowly and attain maturity at small 
a

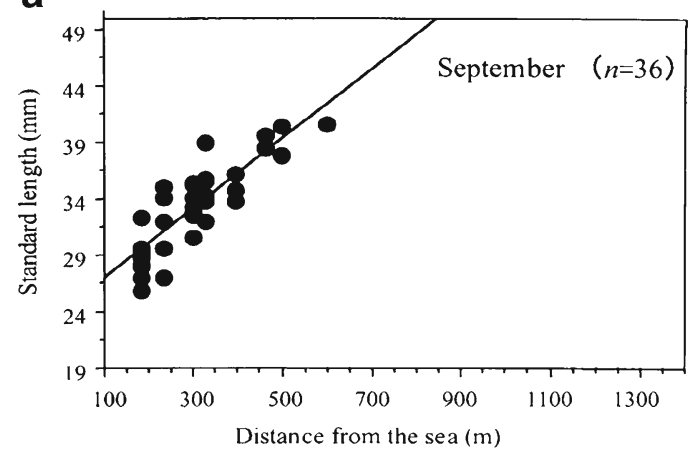

C

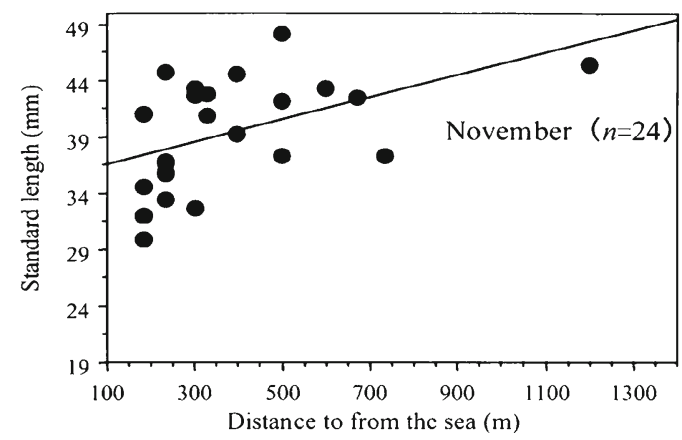

Fig. 7 Relationships between the distance to the collection site from the sea (Dn) and the standard length of juvenile Cottus hangiongensis collected in each sampling site of the Daitobetsu River in the period from September 2005 to February 2006. a

body size and younger ages, whereas juveniles that migrate to the upstream area and stay there grow faster and mature at larger body sizes and older ages (Goto 1989a, 1990, 1993a).

Recently, similar life-history variation was reported in the male Japanese fluvial sculpin $C$. pollux by Natsumeda et al. (2013). They found that the variation in life-history traits for males of the congeneric $C$. pollux occurred in relation to nest abundance along a stream course. From this, they concluded that such life history variation was caused by different sexual selection regimes related to differences in nest abundance between the two research sites. However, this may be not the case in amphidromous $C$. hangiongensis, because of its different spawning ecology from that of fluvial C. pollux as follows: in the population of $C$. hangiongensis, spawning occurs in a restricted part of the downstream area after the mature females and males gather from the original habitats to the spawning area (Goto 1988), such that different sexual selection regimes found in the $C$. pollux population
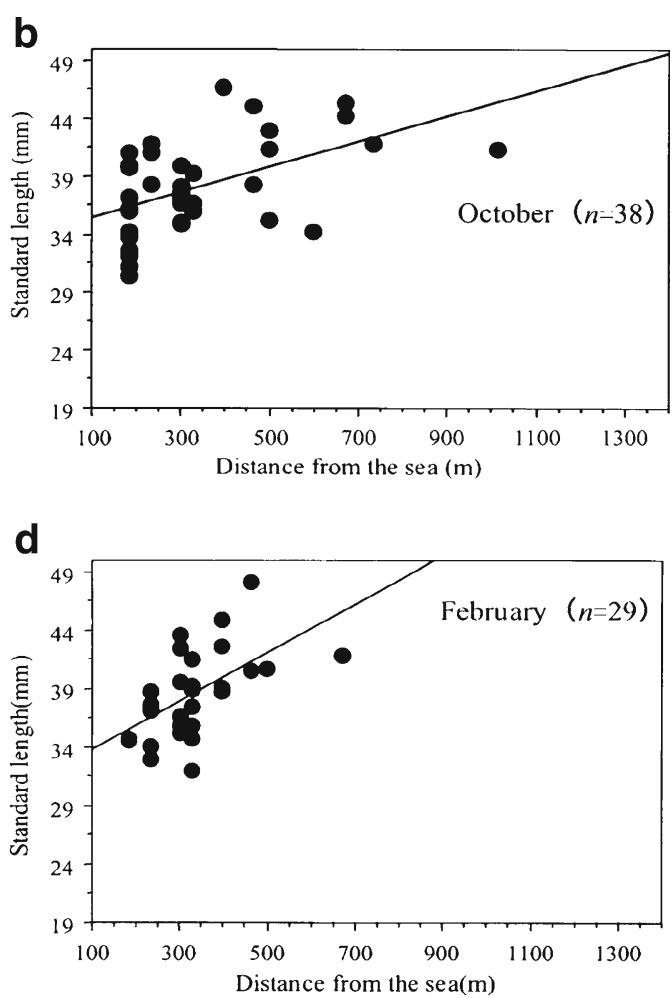

data in September 2005, b data in October 2005, c data in November 2005 and d data in February 2006. The line in each of figures (a-d) indicates a regression showing a significant positive correlation between the two variables

probably do not function in the population of $C$. hangiongensis.

Therefore, based on our current study, it is possible to consider that this clinal variation of life-history traits within a single gene pool of $C$. hangiongensis population may be adaptive for possible exploitation of broad and heterogeneous habitats along the course of a river, and may stem from the plastic phenotypic responses of juvenile fish to the heterogeneous environments in which they are migrating along the course of a steep mountainous river.

Acknowledgments We are grateful to T. Noda, T. Kitamura and M. Uranishi of Graduate School of Fisheries Sciences, Hokkaido University for help in collecting the fish samples, and invaluable technical support for ecological field survey. This work was partly supported by Grant-in-Aid (No. 15405008) for Scientific Research, Japan Society for the Promotion of Science to AG. The field surveys and fish collections carried out in this study comply with the current laws in Japan.

Open Access This article is distributed under the terms of the Creative Commons Attribution License which permits any use, distribution, and reproduction in any medium, provided the original author(s) and the source are credited. 


\section{References}

Bagenal TB (1971) The interrelation of the size of fish eggs, the date of spawning and the reproductive cycle. J Fish Biol 3:207-219

Baker JA, Foster SA (2002) Phenotypic plasticity for life history traits in a stream population of the threespine stickleback, Gasterosteus aculeatus L. Ecol Freshw Fish 11:20-29

Candolin U (1998) Reproduction under predation risk and the trade-off between current and future reproduction in the threespine stickleback. Proc R Soc Lond B 265:11711176

Dewitt TJ, Scheiner SM (2004) Phenotypic Plasticity: Functional and Conceptual Approaches. Oxford University Press, Oxford

Englbrecht CC, Largiader CR, Hanfling B, Tautz D (1999) Isolation and characterization of polymorphic microsatellite loci in the European bullhead Cottus gobio L. (Osteichthyes) and their applicability to related taxa. Mol Ecol Notes 8:19571969

Excoffier L, Laval G, Schneider S (2005) Arlequin (version 3.0): An integrated software package for population genetics data analysis. Evol Bioinform Online 1:47-50

Goto A (1981) Life history and distribution of a freshwater sculpin, Cottus hangiongensis. Bull Fac Fish Hokkaido Univ $32: 10-21$

Goto A (1986) Movement and population size of the river sculpin Cottus hangiongensis in the Daitobetsu River of southern Hokkaido. Jpn J Ichthyol 32:421-430

Goto A (1987a) Polygyny in the river sculpin, Cottus hangiongensis (Pisces: Cottidae), with special reference to male mating success. Copeia 1987:32-40

Goto A (1987b) Life history variation in males of the river sculpin, Cottus hangiongensis, along the course of a river. Environ Biol Fish 19:82-92

Goto A (1988) Reproductive behavior and homing after downstream spawning migration in the river sculpin, Cottus hangiongensis. Jpn J Ichthyol 34:488-496

Goto A (1989a) Growth patterns, and age and size at maturity in female Cottus hangiongensis, with special reference to their life-history variation. Jpn J Ichthyol 36:90-99

Goto A (1989b) Growth differences in males of the river-sculpin Cottus hangiongensis along a river course, a correlation of the life-history variation. Environ Biol Fish 24:241249

Goto A (1989c) Reproductive styles and strategies in freshwater sculpins. In: Goto A, Maekawa K (eds) Reproductive Behaviors in Fish: the Modes and Strategies. Tokai University Press, Tokyo, pp 73-84

Goto A (1990) Alternative life-history styles of Japanese freshwater sculpins revisited. Environ Biol Fish 28:101-112

Goto A (1993a) Clinal life-history variation in the river-sculpin Cottus hangiongensis: an example of phenotypic plasticity. Jpn J Ichthyol 39:363-370

Goto A (1993b) Duration of male mating activity and male mate choice in the river-sculpin, Cottus hangiongensis. Jpn J Ichthyol 40:269-272

Goto A, Arai T (2006) Diverse migratory histories of Japanese Trachidermus and Cottus species (Cottidae) as inferred from otolith microchemistry. J Fish Biol 68:1731-1741
Goto A, Nakano S (1993) Distribution and ecology of freshwater fishes in Hokkaido. In: Higashi S, Osawa A, Kanagawa K (eds) Biodiversity and ecology in the northernmost Japan. Hokkaido Univ. Press, Sapporo, pp 113-126

Henderson PA, Holmes RHA, Bamber RN (1988) Size selective overwintering mortality in the sand smelt, Atherina boyeri Risso, and its role in population regulation. J Fish Biol 33:221-234

Hendry AP, Berg OK, Quinn TP (1999) Condition-dependence and adaptation-by-time: breeding date, life history, and energy allocation within a population of salmon. Oikos 85:499514

Jonsson N, Jonsson B, Fleming IA (1996) Does early growth cause phenotypically plastic response in egg production of Atlantic Salmon. Funct Ecol 10:89-96

Kawecki TJ, Stearns SC (1993) The evolution of life histories in spatially heterogeneous environments: optimal reaction norms revisited. Evol Ecol 7:155-174

Lobon-Cervia J, Utrilla CG, Rincon PA, Amezcua F (1997) Environmentally induced spatio-temporal variations in the fecundity of brown trout Salmo trutta L.: trade-offs between egg size and number. Freshw Biol 38:277288

Metcalfe N, Monaghan P (2001) Compensation for a bad start: grow now and pay later? Trends Ecol Evol 16:254-260

Morita K, Yamamoto S, Takeshima Y, Matsuishi T, Kanno Y, Nishimura K (1999) Effect of maternal growth history on egg number and size in wild white-spottrd char (Salvelinus leucomaenis). Can J Fish Aquat Sci 56:1585-1589

Natsumeda T, Yuma M, Hori M (2013) Variation in life-history traits of male Japanese fluvial sculpin Cottus pollux in relation to nest abundance along a stream course. Environ Biol Fish. doi:10.1007/s10641-013-0108-8

Poizat G, Rosecchi E, Crivelii AJ (1999) Emprical evidence of a trade-off between reproductive effort and expectation of future reproduction in female three-spined sticklebacks. Proc R Soc Lond B 266:1543-1548

Poizat G, Rosecchi E, Crivelii AJ (2002) Life-history variation within a three-spined stickleback population in the Camargue. J Fish Biol 60:1296-1307

R Development Core Team (2008) R: A language and Environment for Statistical Computing. R Foundation for Statistical Computing, Vienna, Austria. ISBN 3-900051-07-0. http:// www.R-project.org

Scheiner SM (1993) Genetics and evolution of phenotypic plasticity. Ann Rev Ecol Syst 24:35-68

Stearns SC (1989) The evolutionary significance of phenotypic plasticity. Bioscience 39:436-445

Stearns SC (1992) The evolution of life histories. Oxford University Press, Oxford

Stearns SC, Koella J (1986) The evolution of phenotypic plasticity in life-history traits, predictions for norm of reaction for age- and size-at-maturity. Evolution 40:893-913

Taborsky B (2006) The influence of juvenile and adult environments on life-history trajectories. Proc R Soc B 273:741750

Tsukamoto K, Kajihara T (1987) Age determination of ayu with otolith. Nippon Suisan Gakkaishi 53:1985-1997

Tsukamoto K, Ishida R, Nara K, Kajihara T (1987) Switching of size and migratory patterns in successive generations of landlocked ayu. Am Fish Soc Symp 1:492-506 
Usui K, Goto A (1987) Characteristics of the large-sized altricial males in the river sculpin, Cottus hangiongensis. Bull Fac Fish Hokkaido University 38:38-49

Ware DM (1975) Relation between egg size, growth, and natural mortality of larval fish. J Fish Res Board Can 32:25032512
Wootton RJ (1990) Ecology of Teleost Fishes. Croom London, London

Yokoyama R, Goto A (2005) Evolutionary history of freshwater sculpins, genus Cottus (Teleostei: Cottidae) and related taxa, as inferred from mitochondrial DNA phylogeny. Mol Phylogenet Evol 36:654-668 